\title{
LA MAGNITUD DE LA MYPE EN EL PERÚ. LIBERTAD PARA ELEGIR LA ESTRUCTURA EMPRESARIAL
}

\author{
THE MAGNITUDE OF "MYPE" IN PERU. FREEDOM TO CHOOSE \\ THE BUSINESS STRUCTURE
}

\author{
Luis Agustín Aliaga Jibaja \\ Universidad Nacional Mayor de San Marcos, Perú \\ https: / / orcid.org/0000-0003-2794-4629
}

\section{Resumen}

El presente artículo tiene por objetivo describir la situación de la micro- y pequeña empresa (mype) considerando estadísticas nacionales y aspectos legales. Resalta la importancia de la mype como el sector con mayor número de emprendimientos en el país y que provee la mayor cantidad de puestos de trabajo a la economía nacional, así como su informalidad. Igualmente, explica la característica individual de su organización empresarial, la limitación legal para acceder a los beneficios de las formas de organización societaria y la necesidad de realizar reformas para fomentar su desarrollo.

Palabras clave: micro- y pequeña empresa, informalidad, empresa, formas societarias.

\begin{abstract}
The purpose of this article is to describe the current situation of micro and small-sized enterprises (mype) considering national statistics and legal aspects. It highlights the importance of the mype sector as it represents the largest number of businesses in the country and it's the largest provider of jobs to the national economy. This article also addresses the informality of the mype sector, the individual characteristics of mypes as business organizations, the
\end{abstract}


legal limitations to access the different incorporation forms and the need to carry out reforms to promote the development of the sector.

Keywords: micro and small business, informality, business, corporate forms.

\section{Introducción}

La micro- y pequeña empresa (mype) en el Perú constituye uno de los sectores empresariales más importantes de la economía nacional. Lamentablemente no ha alcanzado el desarrollo esperado y la mayoría de este tipo de empresas se desempeña en la informalidad. La participación que tiene este sector en la economía, como el más importante generador de puestos de trabajo y de ingresos para los ciudadanos más deprimidos económicamente y con menos oportunidades, exige que el Estado y la sociedad, en general, analicen a profundidad su situación y hagan cambios radicales para brindarle un ambiente de mayores alternativas y posibilidades de desarrollo.

Actualmente se considera que el desarrollo de un país debe ser un proceso integral y sostenible, y no solo limitarse al crecimiento económico, pues debe atender al ser humano en sus principales manifestaciones, así como a la naturaleza o medio ambiente que lo rodea. En este trabajo, no obstante, se asume que una forma inicial de obtener ese objetivo integral y estable es promover el crecimiento económico de todos los ciudadanos, especialmente de aquellos que cuentan con menores recursos económicos. Ya a inicios de los años setenta, Oswaldo Sunkel y Pedro Paz definían al desarrollo de la siguiente forma:

El problema fundamental del desarrollo de una estructura subdesarrollada aparece así como la necesidad de superar su estado de dependencia, transformar su estructura para obtener una mayor capacidad autónoma de crecimiento y una reorientación de su sistema económico que permita satisfacer los objetivos de la respectiva sociedad. En otros términos, el desarrollo de una unidad política y geográfica nacional significa lograr una creciente eficacia en la manipulación creadora de su medio ambiente natural, tecnológico, cultural y social, así como de sus relaciones con otras unidades políticas y geográficas ${ }^{1}$.

1 Oswaldo Sunkel y Pedro Paz, El subdesarrollo latinoamericano y la teoría del desarrollo (México: Siglo XXI, 1970), 37. 
Dos décadas más tarde, las Naciones Unidas, como señala Marcel Valcárcel, expresan un concepto de desarrollo centrado en la persona humana.

El aporte de Amartya Sen, Paul Streeten, Mahbud al Haq, Keith Griffin, John Williamson, y otros académicos provenientes de diversas canteras de la economía está detrás. El Primer Informe del Desarrollo Humano señala que: “El desarrollo humano es un proceso mediante el cual se amplían las oportunidades de los individuos, las más importantes de las cuales son una vida prolongada y saludable, el acceso a la educación y el disfrute de un nivel de vida decente. Otras oportunidades incluyen la libertad política, la garantía de los derechos humanos y el respeto a sí mismo..." (1990) ${ }^{2}$.

Los estudiosos del desarrollo en general - y en especial del latinoamericano-, sostienen desde hace muchos años la necesidad de incluir dentro del proceso de desarrollo económico formal de los países de nuestra región a los grupos excluidos del sistema, y a pesar de las décadas transcurridas, esa situación permanece hasta nuestros días. Así lo planteaban Sunkel y Paz:

... para ser eficaces y permanentes los reordenamientos de esta naturaleza, solo pueden basarse en la participación social, política y cultural activa de nuevos grupos sociales antes excluidos o marginados, y esa participación debe hacerse presente tanto en la formulación de los objetivos de la sociedad como en la tarea de alcanzarlos. Se trata, en último término, de procesos en los cuales nuevos grupos sociales, que fueron "objeto" del desarrollo, pasan a ser "sujeto" de ese proceso.

En nuestros países, solo grupos minoritarios participan y se benefician de los esfuerzos de desarrollo, a veces muy importantes, que se han llevado a cabo, y esto cuando los sectores marginados crecen en número absoluto y a veces incluso en proporción relativa. El desarrollo, por el contrario, ha sido conseguido generalmente mediante un proceso intencionado donde algunos de los grupos socioeconómicos, hasta entonces marginados, han participado en forma creciente, tanto en la definición de los objetivos como en las tareas concretas y en los beneficios del proceso ${ }^{3}$ [cursivas añadidas].

En el caso particular del Perú, teniendo en cuenta la situación de pobreza que se vive en el país y la cantidad de peruanos que forman la clase me-

2 Marcel Valcárcel, Génesis y evolución del concepto y enfoques sobre el desarrollo (Lima: Pontificia Universidad Católica del Perú, 2006), 25, https://www.uv.mx/mie/files/2012/10/SESION6-Marcel-Valcarcel-Desarrollo-Sesion6.pdf

3 Sunkel y Paz, El subdesarrollo latinoamericano y la teoría del desarrollo, 38. 
dia - sectores que comprenden a millones de personas que no gozan de los beneficios del sistema económico en general ni de la formalidad-, se hace necesaria una especial dedicación para brindarles mayores alternativas que hagan posible su desarrollo empresarial privado, teniendo en cuenta que es este sector, y no el Estado, el que debe generar los puestos de trabajo que requiere una economía sana.

Considerando que las mypes congregan a la mayor cantidad de empresarios del país, que en su gran mayoría ellos se organizan como negocios individuales, que generan la mayor cantidad de puestos de trabajo a nivel nacional y teniendo en cuenta, además, la coyuntura actual de la sociedad peruana, surge la siguiente pregunta: ¿cómo han colaborado y de qué forma pueden ayudar el derecho y la norma legal al crecimiento económico de este sector?

\section{Libertad del empresario para elegir: la sociedad unipersonal}

Es en el terreno de la organización empresarial donde el derecho ha realizado uno de los aportes más importantes al desarrollo económico, gracias a las diversas formas que cada ordenamiento jurídico ha creado con la finalidad de que las diversas expresiones de los negocios o empresas que se constituyan se desarrollen de manera más ordenada, atendiendo a la voluntad individual o colectiva de los ciudadanos.

La empresa se ha definido de diversas formas, pero siempre se resalta su perfil económico. Así, se puede, en general, entender como empresa a toda unidad económico-social o unidad productiva organizada por una o más personas (elemento humano) que tiene por finalidad generar beneficios o utilidades mediante la administración de los factores de la producción, el capital y el trabajo.

La empresa es la unidad económica de base en la cual se desenvuelve el proceso productivo. Para Ronald Harry Coase, premio nobel de economía 1991, la empresa («the firm»), en la teoría económica moderna, es una organización que transforma entradas en salidas. Las entradas son los bienes comprados por la empresa y luego transformados en productos que vende: «The firm in modern economic theory is an organization which transforms inputs 
in outputs... (the inputs a firm buys and the output it sells)... ${ }^{4}$. Igualmente, el mismo Coase señala que la empresa consiste en un sistema de relaciones que surge cuando la dirección de los recursos depende de un empresario: «A firm, therefore, consists of the system of relationships which comes into existence when the direction of resources is dependent on an entrepreneur» ${ }^{5}$.

El concepto jurídico de empresa no está claramente establecido. Se suele llegar a él de forma indirecta, a través de la definición de empresario: persona física o jurídica que, de forma habitual y no ocasional, realiza en nombre propio una actividad económica productiva dirigida al mercado, a la cual se la denomina, en consecuencia, «actividad empresarial».

Desde el punto de vista jurídico mercantil, se puede definir empresa como una unidad patrimonial autónoma y compleja en la que se integra un conjunto organizado de bienes, derechos y obligaciones, bajo la titularidad y dirección del empresario. La empresa constituye, así, un centro de imputación jurídica de la economía moderna, un instrumento que canaliza actividades económicas con fin lucrativo o sin fines de lucro, ya que lo que interesa es la actividad empresarial que se lleva a cabo.

En algunas legislaciones se considera a la empresa como una persona jurídica, pues se tiende a unificar el tratamiento jurídico de sus diversos elementos y se le atribuye el carácter de «persona», en tanto que no es un simple conjunto de medios de producción inertes, sino una nueva persona con vida propia.

Nuestro ordenamiento jurídico ofrece a los ciudadanos diversos modelos de estructura organizacional para realizar sus emprendimientos. Se trata de diversas formas jurídicas, cada una de las cuales resulta una entre varias opciones para hacer empresa. De esta manera, el ciudadano puede actuar en forma personal, individual (en la Sunat se la conoce como «persona natural con negocio»), o bien constituyendo una persona jurídica, la empresa individual de responsabilidad limitada (E. I. R. L.). Tiene, asimismo, la posibilidad de hacer negocio como una persona jurídica societaria; en este caso debe asociarse, necesariamente, con otra persona (socio), eligiendo cualquiera de las formas

4 Ronald Coase, The firm, the market and the law (Chicago: The University of Chicago Press, 1988), 5.

5 R. H. Coase, «The nature of the firm», Economica 4, n. ${ }^{\circ} 16$ (1937): 393, https:/ /onlinelibrary. wiley.com/doi/epdf/10.1111/j.1468-0335.1937.tb00002.x 
societarias establecidas en la Ley General de Sociedades ${ }^{6}$, como la sociedad comercial de responsabilidad limitada (S. C. R. L.) o la sociedad anónima (S. A.).

Las formas societarias son estructuras empresariales organizadas y determinadas por la ley. Brindan, entre otros, los siguientes beneficios: personalidad jurídica, responsabilidad limitada, división del trabajo y especialización, organización empresarial flexible, determinación de responsabilidades internas, representación externa, responsabilidades claras de sus administradores, posibilidad de dividir el capital en acciones o participaciones que faciliten obtener más capital, la capacidad de asociarse a través de contratos, la posibilidad de emitir títulos u obtener directamente crédito en entidades financieras, adquirir seguros y otros beneficios que brinda la actividad empresarial formal.

Sin embargo, en el caso de las mypes — que constituyen la gran mayoría de emprendimientos en el Perú, como se explicará más adelante-, el sistema legal empresarial no les brinda alternativas suficientes con los beneficios organizacionales necesarios para incentivar su desarrollo empresarial; y es que, si bien los ciudadanos que desean hacer empresa en forma colectiva pueden, en principio, escoger alguna de las formas previstas en la ley, aquellas personas naturales que desean hacer negocio en forma individual solo pueden desarrollar su empresa como «persona natural con negocio» o como E. I. R. L. La razón es que existe un requisito establecido en la Ley General de Sociedades, «la pluralidad de socios», que establece un mínimo de dos personas para constituir una sociedad ${ }^{7}$.

Las empresas organizadas como personas individuales no gozan de los beneficios antes mencionados; y las E. I. R. L. no los tienen todos. Esta forma jurídica, además, presenta limitaciones que impiden el crecimiento del negocio. Así pues, si un ciudadano desea ser empresario y recibir los beneficios mencionados, no puede hacerlo en forma individual: necesita asociarse, buscar otra persona que lo acompañe en el negocio.

La norma legal que establece la pluralidad de socios como requisito societario es una limitación o impedimento para que los micro- y pequeños empresarios puedan acceder a los beneficios de las estructuras legales que se regulan en la Ley General de Sociedades, pues al no poder cumplir con dicha exigencia, se les hace imposible formar sociedades. Algunos empresarios se

6 Ley General de Sociedades, Ley N. 26887 (publicada el 19 de diciembre de 1997).

7 Artículo 4 de la Ley General de Sociedades. 
ven obligados a conseguir uno o más socios, a pesar de que en realidad desean hacer negocio en forma individual; otros —inclusive en la mediana empresa- deciden utilizar la figura del testaferro para «crear» formalmente un "socio fantasma», inexistente como socio en la realidad, pero que formalmente aparece como un segundo socio, y cuya participación nominativa permite cumplir con el requisito de la pluralidad.

En el ordenamiento jurídico nacional, la existencia legal de la sociedad unipersonal continúa siendo un tema pendiente. Algunos autores nacionales se han pronunciado a favor de regular un tipo de sociedad con un solo socio ${ }^{8}$, sustentando su posición con diversos argumentos que compartimos; sin embargo, formalmente, la pluralidad de socios sigue siendo, hasta la fecha, uno de los requisitos legales para la existencia jurídica de una sociedad.

Para Alfonso Montoya Stahl, profesor de la materia en la Facultad de Derecho de la Pontificia Universidad Católica del Perú (PUCP), la unipersonalidad de las sociedades debe ser permitida por la legislación societaria:

... las funciones que desempeñan actualmente las sociedades justifican plenamente una regulación societaria que permita la unipersonalidad originaria o sobrevenida en forma irrestricta (es decir, no sujeta a limitaciones temporales o en función del tipo de sujeto), al menos en las formas societarias más empleadas: la sociedad anónima y la sociedad comercial de responsabilidad limitada... 9 .

Asimismo, Emilio Figueroa Reynoso, profesor de la UPC, considera que:

... comprenderemos que gracias a la existencia y regulación de la unipersonalidad societaria, y en forma de una sociedad unipersonal dentro de la Ley General de Sociedades, se lograría una meta significativa, la cual sería dar un paso más en lo referido a la implementación de nuevas formas jurídicas para hacer negocio. Dejar de pensar únicamente en el término "sociedad" según la visión lingüística y comenzar a entender el concepto jurídico de la sociedad como una institución, independiente de su formación y de sus miembros ${ }^{10}$.

8 Pedro Flores Polo, Alfonso Montoya Stahl, Daniel Echaíz Moreno, Emilio Figueroa Reinoso y Paolo D’Onofrio, entre los más importantes.

9 Alfonso Montoya Stah, «'Uno es compañía...': la conveniencia de regular la sociedad unipersonal en el Perú», en Derecho Societario, ed. Ius et Veritas (Lima: Ediciones Legales, 2011), 788.

10 Emilio Figueroa Reinoso, La sociedad unipersonal: la importancia de su regulación en el derecho societario (Lima: Universidad Peruana de Ciencias Aplicadas. 2016), 18. 
Como bien señalan estos autores y otros que han estudiado la legislación comparada, muchos países ya han aprobado la existencia de la sociedad unipersonal, inclusive en Latinoamérica — tal es el caso de Colombia-, y especialmente para la micro- y pequeña empresa, como es el caso de la Unión Europea, que ha emitido directivas para que los Estados miembros regulen las sociedades de responsabilidad limitada de socio único ${ }^{11}$; España fue uno de los primeros países en adaptar su legislación a la directiva europea. El caso de Estados Unidos es singular, porque en su legislación societaria existe la figura de la «corporación», que permite la existencia de dicha sociedad con un solo socio.

Sin embargo, a pesar de que una gran parte de la doctrina nacional ya está de acuerdo con la sociedad unipersonal - y hasta se ha aprobado un anteproyecto de Ley General de Sociedades-, aún no recibe la aprobación de los legisladores. Es probable que todavía existan posiciones discrepantes sobre la existencia de la sociedad unipersonal, probablemente porque, de un lado, todavía prevalece la posición tradicionalista de considerar a la sociedad como un contrato, no obstante que la Ley General de Sociedades vigente ya no señala expresamente esta situación; y de otro lado, debido al significado y la etimología del término sociedad ${ }^{12}$, que alude a un conjunto de personas, considerando una base plural y no singular.

\section{Realidad de la micro- y pequeña empresa en el Perú}

Además de los argumentos doctrinarios, es muy importante analizar la realidad del micro- y pequeño empresario, pues esto permitirá entender mejor sus necesidades y obtener más elementos de juicio para sustentar su derecho a elegir con libertad y amplitud entre formas empresariales que realmente le otorguen beneficios y promuevan su negocio. Asimismo, en forma paralela, se deben proponer cambios para sincerar la situación organizacional de muchos

11 Directiva 89/667/CEE del Consejo de las Comunidades Europeas del 21 de diciembre de 1989 y Directiva 2009/102/CE del Parlamento Europeo del 16 de setiembre del 2009.

12 Para la Real Academia Española, sociedad viene del latín societas y significa 1. f. Conjunto de personas, pueblos o naciones que conviven bajo normas comunes. 2. f. Agrupación natural o pactada de personas, organizada para cooperar en la consecución de determinados fines. 3. f. Agrupación natural de algunos animales. 4. f. Agrupación comercial de carácter legal que cuenta con un capital inicial formado con las aportaciones de sus miembros. 
empresarios, inclusive de la mediana y gran empresa, que constituyen sus sociedades con socios que solo son «testaferros» $\mathrm{y}$ «superminoritarios».

En cuanto a la micro- y pequeña empresa, es el sector económico empresarial más grande del país desde el punto de vista del número de emprendimientos involucrados; igualmente, provee la mayor parte de los puestos de trabajo en el país, en comparación con el sector formal en general. Al mes de diciembre del año 2018, el sector informal empresarial había ocupado al 56.8 \% de la PEA (INEI) ${ }^{13}$, puestos de trabajo que ni el Estado ni el sector empresarial privado formal han podido ofrecer ni fomentar de forma sostenida.

Una economía sana es aquella que brinda y genera puestos de trabajo con vocación de permanencia, como son los que brinda el sector empresarial privado, y que permite obtener ingresos y sustento especialmente a las grandes mayorías del país.

El Estado, a través de las normas legales, regula las relaciones jurídicas de los ciudadanos, personas naturales o jurídicas, y del propio Estado. Por mandato constitucional, el Estado tiene la obligación de orientar el desarrollo general del país, especialmente de las grandes mayorías, dándole contenido a las normas e instituciones jurídicas, ajustando y modernizando sus definiciones, a fin de brindar facilidades a los agentes económicos para que puedan organizarse y cumplir su rol de generadores de riqueza y proveedores de empleo, promoviendo las pequeñas empresas en todas sus modalidades.

La Constitución Política del Perú (1993) establece en su artículo 59:

El Estado estimula la creación de riqueza y garantiza la libertad de trabajo y la libertad de empresa, comercio e industria. El ejercicio de estas libertades no debe ser lesivo a la moral, ni a la salud, ni a la seguridad, públicas. El Estado brinda oportunidades de superación a los sectores que sufren cualquier desigualdad; en tal sentido, promueve las pequeñas empresas en todas sus modalidades [cursivas añadidas].

A pesar de esta obligación constitucional, el sector de la micro- y pequeña empresa, que representa más del $99 \%$ del total de las unidades empresariales

13 Instituto Nacional de Estadística e Informática (INEI), Producción y empleo informal en el Perú: cuenta satélite de la economía informal 2007-2018 (Lima: INEI, 2019), 5, 57 (cuadro 3.1a), https://www.inei.gob.pe/media/MenuRecursivo/publicaciones_digitales/Est/Lib1701/ libro.pdf 
del país, es el sector económico más vulnerable y con menos posibilidades legales para su desarrollo, pues, entre otros aspectos, sus unidades se encuentran organizadas principalmente como negocios individuales sin posibilidades de aprovechar los beneficios organizativos de los que sí gozan las empresas organizadas como sociedades.

Las cifras que se mencionarán a continuación se basan en los informes estadísticos oficiales del Instituto Nacional de Estadística e Informática (INEI) publicados hasta la fecha - los cuales se refieren al año 2018-, que permiten analizar y comparar el sector formal con el sector informal del empresariado nacional.

Así, para el año 2018 existían 9,873,033 unidades empresariales, tanto formales como informales, en todo el país ${ }^{14}$. De este total, 9,850,866, es decir, más del 99 \%, correspondía al sector de la micro- y pequeña empresa. De estos emprendimientos, a su vez, 7,480,000 eran informales, porque, según el INEI, no se encuentran organizados como sociedades (o personas jurídicas) y carecen de $\mathrm{RUC}^{15}$. El número de mypes formales asciende a 2,370,866 (organizadas como sociedades, empresas individuales de responsabilidad limitada o personas naturales con negocio, todas con RUC). Estos datos permiten concluir que para el año 2018 más del $75 \%$ de los negocios en el país eran informales.

Otro aspecto que se puede apreciar de las cifras oficiales del INEI es que la gran mayoría de los micro- y pequeños empresarios se organizan como personas naturales en forma individual, arriesgando su capital personal y familiar en el negocio y sin poder utilizar los beneficios que la ley establece para la organización societaria.

Analizando las estadísticas del INEI, se puede concluir que más del $93.5 \%$ del total de unidades empresariales existentes en el país en diciembre de 2018 $(9,240,746$ empresas) se organizaban empresarialmente como personas individuales, de las cuales 1,760,746 tenían RUC y eran consideradas, así, «personas naturales con negocio» (formales), mientras que 7,480,000 eran personas naturales sin RUC (informales) ${ }^{16}$.

14 INEI, Producción y empleo informal en el Perú, 2007-2018, 57; e INEI, Perú: estructura empresarial 2018, (Lima: INEI, 2019), 9, 29. https://www.inei.gob.pe/media/MenuRecursivo/ publicaciones_digitales/Est/Lib1703/libro.pdf

15 RUC: siglas del Registro Único de Contribuyentes, otorgado por la Superintendencia Nacional de Aduanas y de Administración Tributaria (Sunat).

16 INEI, Producción y empleo informal en el Perú 2007-2018, 57; e INEI, Perú: estructura empresarial 2018,9 . 
Otras conclusiones se desprenden del estudio de estas cifras: más del $95.5 \%$ de los empresarios en el Perú $(9,425,535)$, al mes de diciembre del 2018, desarrollaban sus negocios como persona natural, es decir, en forma individual, y solo el $4.5 \%$ de todas las unidades empresariales existentes en el país estaba organizado como persona jurídica o utilizando alguno de los modelos establecidos en la Ley General de Sociedades y la Ley de la Empresa Individual de Responsabilidad Limitada.

No obstante su magnitud, el sector de la micro- y pequeña empresa es el más vulnerable y el menos desarrollado del ámbito empresarial del país. Esto se debe a diversos motivos, entre los cuales se pueden señalar: la escasa inversión, que les impide soportar los costos y sobrecostos laborales; la imposibilidad de acceder al crédito formal; la carencia de tecnificación; la falta de una buena organización; la inexistencia en la ley de alternativas de organización empresarial que les brinden los beneficios con los que cuentan las formas societarias, forma jurídica que es utilizada fundamentalmente por la mediana y gran empresa que invierte grandes capitales.

Según el INEI, hasta el mes de diciembre del 2018 existían en el Perú 7,480,000 emprendimientos informales, cuyos propietarios eran personas naturales que trabajaban en forma individual, sin contar con RUC y sin utilizar la forma jurídica de sociedad.

Para efectos estadísticos, el INEI considera «negocio o emprendimiento informal» a aquel que no se encuentra registrado en la Sunat (y que, por lo tanto, no tiene RUC) ni figura en el Directorio Central de Empresas y Establecimientos (DCEE), el cual registra las unidades económicas formales constituidas a nivel nacional. El concepto de informalidad, sin embargo, es bastante más amplio, como señalan algunos autores. Tal es el caso de Hernando de Soto y el ILD (Instituto Libertad y Democracia):

No son informales los individuos sino sus hechos y actividades. La informalidad no es tampoco un sector preciso ni estático de la sociedad, sino una zona de penumbra que tiene una larga frontera con el mundo legal y donde los individuos se refugian cuando los costos de cumplir las leyes exceden a sus beneficios; en la mayoría, se desobedecen disposiciones legales precisas... ${ }^{17}$.

17 Hernando de Soto, El otro sendero, 3. ${ }^{\text {a }}$ ed. (Lima: Ausonia, 1986), 12-13. 
Los negocios informales no cumplen, por lo menos, con alguno de los requisitos legales fundamentales para constituirse y operar ${ }^{18}$, y no aportan al erario nacional mediante el pago de tributos, como el impuesto a la renta; pero, además, no son controlados por las entidades fiscalizadoras, incumplen muchas normas legales — como las laborales y las contables, entre otras- y generan trabajo informal. Cabe precisar que dentro del sector informal no se considera la ilegalidad, es decir, no se incluyen las actividades que realizan transacciones punibles o tipificadas como delitos (contrabando, tráfico ilícito de drogas, minería ilegal, entre otras).

Conviene destacar que, según los registros del INEI, para diciembre del 2018 el número de empresas formales se había incrementado en 89,522 con relación al año 2017, pues había pasado de 2,303,511 a 2,393,033. Para dicho organismo estatal, una empresa formal es aquella que está inscrita en la Sunat, es decir, que tiene número de RUC y se halla registrada en el Directorio Central de Empresas y Establecimientos (DCEE) del INEI, el cual toma como base la información de la Sunat y de la Superintendencia Nacional de los Registros Públicos.

Dentro de este número de empresas formales se encuentran aquellas organizadas como personas naturales con negocio, las empresas públicas y todas las empresas que utilizan alguna de las formas jurídicas de organización permitidas por la legislación peruana: las E. I. R. L., las sociedades anónimas (en todas sus modalidades), las S. C. R. L. y las demás formas societarias previstas (según los textos legales vigentes a diciembre del 2018) en la Ley General de Sociedades y las personas jurídicas establecidas en el Código Civil.

Asimismo, entre el año 2017 y el año 2018 ha existido un aumento de 346,522 nuevos emprendimientos, unidades productivas o negocios, considerando todos los emprendimientos, tanto aquellos ubicados en el sector formal como los que se desenvuelven en el sector informal ${ }^{19}$.

Es importante tener en cuenta cómo estaba organizado jurídicamente el sector formal empresarial al año 2018, según las estadísticas del INEI ${ }^{20}$ : del

18 Para el INEI, el sector informal comprende las unidades productivas no constituidas en sociedad que no se encuentran registradas en la administración tributaria. Ver la introducción de: INEI, Perú: estructura empresarial 2018, 5.

19 INEI, Producción y empleo informal en el Perú 2007-2018, 5, 57 (cuadro 3.1a); e INEI, Producción y empleo informal en el Perú: cuenta satélite de la economía informal 2007-2017, (Lima: INEI, 2018), 5 , 53 (cuadro 3.1a), https://www.inei.gob.pe/media/MenuRecursivo/publicaciones_digitales/ Est/Lib1589/libro.pdf; INEI, Perú: estructura empresarial 2018, 5.

20 INEI, Perú: estructura empresarial 2018, 29. 
total de empresas formales $(2,393,033)$, el $73.6 \%(1,760,746)$ se organizaba como empresario individual; el $12.5 \%(299,278)$, como sociedad anónima; el $2.6 \%(61,558)$, como sociedad comercial de responsabilidad limitada; el $7.7 \%$ $(186,229)$, como empresas individuales de responsabilidad limitada; y el $0.4 \%$ $(9,489)$, como sociedad civil.

Del análisis de estas cifras, se puede concluir que en el año 2018 solo 370,325 empresas formales estaban organizadas como sociedad ${ }^{21}$, cantidad que, en relación con el total de las empresas existentes en el Perú en aquel momento, representaba menos del $3.8 \%$ del total de negocios formales. Asimismo, se observa que más del 96 \% del total de empresas formales del país se organizaban en forma individual; de ellas, menos del $1.8 \%$ estaban organizadas como personas jurídicas individuales (E. I. R. L.); y el resto, más de $98 \%$, como persona natural con negocio.

Según las mismas estadísticas, no solo el sector informal, sino también la gran mayoría del empresariado formal (73.6 \%) se organizaba, a diciembre del año 2018, como empresario individual y no constituía ni organizaba su empresa como sociedad. ¿Será que los empresarios no desean constituirse como persona jurídica? ¿Acaso no les agradan las características organizativas ni los beneficios de los que gozan las sociedades? Estas preguntas plantean temas que el Estado debe investigar y resolver para entender mejor dicho sector y dictar normas que incentiven su desarrollo.

Al empresario individual, en general, sí le gustaría organizarse como sociedad y gozar de sus beneficios. No puede hacerlo, sin embargo, por varias razones. Una de las más importantes es que la mayoría de los empresarios del sector de la micro- y pequeña empresa desea ser el único propietario de su negocio con la finalidad de tomar decisiones sin consultar a otra persona; quiere, de esta manera, evitar dilaciones e inclusive una eventual discrepancia que pudiese truncar la toma de decisiones de todo nivel e importancia. Esto se aprecia en las respuestas dadas en las últimas encuestas nacionales de hogares (ENAHO) del INEI y en aquellas realizadas por el autor del presente artículo entre pequeños comerciantes de los conos de Lima Metropolitana. Así pues, el requisito de la pluralidad de socios constituye una barrera legal de entrada para acceder a la estructura societaria.

21 S. A. $=12.5 \%$; S. R. L. $=2.6 \%$ y sociedad civil $=0.4 \%$ de las empresas formales. 
La organización individual y el sector informal se están convirtiendo en una realidad constante. Parece inevitable la informalidad en los pequeños negocios, especialmente en la microempresa, porque, a pesar de que la situación de informalidad pone en riesgo su patrimonio personal y no brinda estímulos al desarrollo empresarial, el sector empresarial informal, según el INEI, siguió creciendo en número. Por ejemplo, del año 2017 al 2018, las unidades empresariales informales pasaron de 7,148,000 a 7,480,000, es decir, hubo un aumento de 332,000. Esto es señal, por un lado, de la difícil situación que atraviesa nuestra economía -agudizada en estos dos últimos años a causa de la pandemia de la covid-19-; y, por otro lado, demuestra que el sector informal empresarial individual continúa siendo la «válvula de escape de la economía» al brindar ocupación y trabajo a las grandes mayorías y clases pobres del país. Por su magnitud y por las características mencionadas, se debería fomentar y brindar al sector de la micro- y pequeña empresa - especialmente al informal- incentivos y mejores posibilidades de organización empresarial para que se desarrolle.

En el lado formal, según avances de los informes estadísticos del $\mathrm{INEI}^{22}$, el número de unidades empresariales formales $(2,734,619)$ aumentó el año 2019 en $14.3 \%$ con respecto al 2018, mientras que en el año 2020 el incremento fue de 1.6 \% en comparación con el 2019, hasta llegar a 2,777,424. Estas cifras indican una desaceleración en la creación de nuevas empresas por motivo de la pandemia, pero también que en el año 2020 el Perú ya se encontraba, de alguna manera, en proceso de recuperación de la crisis provocada por la covid-19, puesto que el número de nuevas empresas formales supera al de aquellas que salieron del mercado.

Como aún no se halla disponible, a la fecha de redacción del presente trabajo, información oficial del INEI más detallada que permita una comparación numérica entre formas empresariales individuales y las sociedades entre los años 2019 y 2020, se ha considerado como referencia el año 2018. Sin embargo, de las cifras expuestas se puede concluir inicialmente que la diferencia entre los empresarios individuales y las sociedades, por lo menos, se mantiene.

22 INEI, «Perú: Stock y variación neta de empresas en el IV trimestre de 2019», Demografía empresarial en el Perú, 4 trimestre 2019, n. ${ }^{\circ} 1$ (febrero 2020): 2, https://www.inei.gob.pe/ media/MenuRecursivo/boletines/demografia_empresarial_ene2020.pdf; INEI, «Perú: Stock y variación neta de empresas en el IV Trimestre de 2020», Demografía empresarial en el Perú, 4 trimestre 2020, n. 1 (marzo 2021): 2, https://www.inei.gob.pe/media/MenuRecursivo/ boletines/boletin_demografia_empresarial_3.pdf 
El Estado ha intentado en diversas ocasiones la formalización de las mypes, pero hasta la fecha no ha tenido éxito. Al respecto, uno de los problemas que aún no se ha tomado en cuenta en las reformas aprobadas es la eliminación del requisito de la pluralidad de socios para constituir sociedades o algún tipo de ellas. Las instituciones jurídicas y las entidades que deben estar al servicio de todos los ciudadanos no han logrado atraer a los agentes económicos de las mypes a la formalidad ni mucho menos promover su permanencia en esta.

Cabe reiterar que el sector informal de las mypes está constituido principalmente por personas o empresarios, dueños individuales de sus respectivos negocios, y que las normas legales que rigen la empresa no les brindan los mismos beneficios que la ley sí concede a aquellos emprendimientos organizados colectivamente, pues se exige la pluralidad de socios (dos como mínimo) para la constitución de sociedades.

De otro lado, resulta pertinente preguntarse: ¿son conscientes tanto el Estado como los empresarios de todo nivel - especialmente los del sector mype formal e informal - de que la empresa es una aventura, un riesgo, y de que, en sociedades como la nuestra, con una economía de mercado — que se basa en la libre competencia y el libre juego de la oferta y la demanda-, el fracaso y la quiebra son parte del desarrollo empresarial, y de que, por esa razón, es muy importante entender que se debe aprender siempre del fracaso para nuevamente empezar con más experiencia?

Inclusive en países donde el desarrollo empresarial es importante y se promueve, muchas veces el número de empresas «nuevas» que se constituyen cada año llega a ser muy similar al número de empresas que fracasan y quiebran; tienen, sin embargo, una economía sana que, además, se sustenta en la pequeña empresa. Un claro ejemplo son los Estados Unidos de América, país donde el número de empresas que cierran o quiebran es muy similar al de aquellas que abren o se constituyen²3. Así, en el año 2015, cuando existían aproximadamente 30 millones de empresas (formales), iniciaron sus operaciones 414,000 nuevas pequeñas empresas formales, mientras que cerraron 396,000. En el Perú, en el año 2018 se crearon 70,547 empresas formales y se

23 Ravinder Kapur, «Estadísticas de pequeños negocios 2019», Camino Financial, 30 de abril de 2020, https://www.caminofinancial.com/es/estadisticas-de-pequenos-negocios/ (se basa en las estadísticas de la Oficina de Censos de los Estados Unidos, y de la Small Business Administration (SBA) del mismo país). 
dio de baja a $45,052^{24}$. El gran problema del Perú es que la micro- y pequeña empresa es fundamentalmente informal (7,480,000 empresas en el año 2018) y no contribuye como debiera al desarrollo económico del país, como sí lo hace en Estados Unidos y otros países.

De otro lado, surgen otras preguntas: ¿quiénes son considerados microy pequeños empresarios?, ¿corresponde establecer un régimen especial para ellos?, ¿por qué?, ¿se debe seguir viéndolos como empresarios de segunda clase y generar excesivos proteccionismos que, más bien, pueden constituir un obstáculo para su desarrollo? ¿O, en todo caso, se podría considerar a este sector como una etapa natural del desarrollo empresarial que debe cumplir con su aportación al Estado y al país como todos los peruanos? Y si es así, ¿cómo se debe manejar esta situación?, ¿por qué hasta la fecha no han funcionado las reformas?

Entre las razones que explican la decisión de la mayor parte de los microy pequeños empresarios del país de organizar su negocio formal en forma individual, se han señalado, entre otras, las siguientes: este tipo de organización representa bajos costos de entrada y salida del mercado; su constitución es sencilla y rápida, no representa mayores trámites; se pueden acoger a regímenes más favorables para el pago de impuestos; pueden contar con documentación contable simplificada; y si la empresa no obtiene los resultados esperados, se puede replantear el giro del negocio sin mayores inconvenientes.

Todas esas razones se sustentan en la realidad de los pequeños empresarios, pues la mayor parte de ellos realizan siempre un análisis costo-beneficio para decidir la forma de hacer negocio formalmente; es necesario tener presente, sin embargo, que solo pueden comparar los costos que representa organizarse como «persona natural con negocio» o como persona jurídica E. I. R. L., mas no como sociedad, ya que no les es posible cumplir con el requisito de la pluralidad de socios.

\section{Palabras finales}

El análisis de la realidad, como se ha visto en las estadísticas, arroja que la mayoría de empresarios individuales elige la informalidad, probablemente

24 INEI, «Perú: Stock y variación neta de empresas», 2020, 2. 
porque los costos que ellos consideran superan largamente los beneficios de ser formal (persona natural con negocio o E. I. R. L.); tiene en cuenta, además, que se trata de negocios que implican una pequeña o pequeñísima inversión y tienen una baja productividad, debido a numerosas falencias. Con todo, representan una alternativa económica viable y muy utilizada que ha permitido que la economía peruana soporte las crisis, pues genera millones de puestos de trabajo e ingresos económicos para las grandes mayorías del país.

Consideramos una excelente noticia y saludamos la posición que se ha tomado en el anteproyecto de Ley General de Sociedades, esfuerzo que data del año 2014 y cuyo texto revisado hasta el año 2020 ha sido aprobado por el Ministerio de Justicia y Derechos Humanos, y publicado en mayo del 2021. En este ya no se exige la pluralidad de socios como requisito para la constitución de sociedades anónimas y sociedades comerciales de responsabilidad limitada; se permitiría, de esta manera, la existencia de sociedades unipersonales. Dicho anteproyecto es resultado de un gran esfuerzo hecho por funcionarios, profesionales y docentes universitarios. De ahí que esperamos su pronto análisis y aprobación en el Congreso de la República. Somos conscientes de que la actual coyuntura política y de pandemia pueden complicar y retrasar su aprobación, pero confiamos en que los argumentos jurídicos planteados por diversos especialistas y la realidad de la situación de las mypes expuesta en el presente documento convenzan a nuestros legisladores y autoridades, y se apruebe esta reforma tan necesaria para el desarrollo de los micro- y pequeños empresarios.

Si bien es cierto que se requieren varios tipos de reformas para fomentar realmente el desarrollo de las mypes, una de ellas debe referirse a la posibilidad legal de constituir una sociedad unipersonal. De ser aprobada esta reforma, recién podría realmente verificarse si la alternativa de organizarse como sociedad les resulta atractiva a los empresarios individuales, considerando los beneficios de la estructura empresarial societaria.

Es probable que muchos opten por esta nueva forma empresarial, pero otros no lo harán. Lo importante es que todos los empresarios individuales del país y quienes deseen administrar sus negocios en forma individual puedan tener la posibilidad real y legal de constituirse en sociedad. De esta manera, tendrían realmente la libertad de elegir de la que hoy carecen. 


\section{REFERENCIAS}

Coase, R. H. «The nature of the firm». Economica 4, n. 16 (1937): 386-405. https:// onlinelibrary.wiley.com/doi/epdf/10.1111/j.1468-0335.1937.tb00002.x

Coase, Ronald. The firm, the market and the law. Chicago: The University of Chicago Press, 1988.

Figueroa Reinoso, Emilio. La sociedad unipersonal: la importancia de su regulación en el derecho societario. Lima: Universidad Peruana de Ciencias Aplicadas, 2016.

Instituto Nacional de Estadística e Informática (INEI). Producción y empleo informal en el Perú: cuenta satélite de la economía informal 2007-2017. Lima: INEI, 2018. https://www.inei.gob.pe/media/MenuRecursivo/publicaciones_digitales/Est/ Lib1589/libro.pdf

Instituto Nacional de Estadística e Informática (INEI). Producción y empleo informal en el Perú. cuenta satélite de la economía informal 2007-2018. Lima: INEI, 2019. https://www.inei.gob.pe/media/MenuRecursivo/publicaciones_digitales/Est/ Lib1701/libro.pdf

Instituto Nacional de Estadística e Informática (INEI). Perú: estructura empresarial 2018. Lima: INEI, 2019. https://www.inei.gob.pe/media/MenuRecursivo/ publicaciones_digitales/Est/Lib1703/libro.pdf

Instituto Nacional de Estadística e Informática (INEI). «Perú: Stock y variación neta de empresas en el IV trimestre de 2019». Demografía empresarial en el Perú, 4 trimestre 2019, n. ${ }^{\circ} 1$ (febrero 2020): 2-3. https:/ / www.inei.gob.pe/media/MenuRecursivo/ boletines/demografia_empresarial_ene2020.pdf

Instituto Nacional de Estadística e Informática (INEI). «Perú: Stock y variación neta de empresas en el IV Trimestre de 2020». Demografía empresarial en el Perú, 4 trimestre 2020 , n. 1 (marzo 2021): 2-3. https:/ / www.inei.gob.pe/media/MenuRecursivo/ boletines/boletin_demografia_empresarial_3.pdf

Kapur, Ravinder. «Estadísticas de pequeños negocios 2019». Camino Financial, 30 de abril de 2020. https://www.caminofinancial.com/es/estadisticas-de-pequenosnegocios/

Montoya Stah, Alfonso. «'Uno es compañía...': la conveniencia de regular la sociedad unipersonal en el Perú», en Derecho Societario, editado por Ius et Veritas, 787-828. Lima: Ediciones Legales, 2011.

Soto, Hernando de. El otro sendero. 3. ${ }^{\text {a }}$ ed. Lima: Ausonia, 1986. 
Sunkel, Oswaldo y Pedro Paz. El subdesarrollo latinoamericano y la teoría del desarrollo. México: Siglo XXI, 1970.

Valcárcel, Marcel. Génesis y evolución del concepto y enfoques sobre el desarrollo. Lima: Pontificia Universidad Católica del Perú, 2006. https://www.uv.mx/mie/ files/2012/10/SESION-6-Marcel-Valcarcel-Desarrollo-Sesion6.pdf

\section{Sobre el autor}

Graduado por la Pontificia Universidad Católica del Perú, con estudios de Maestría en la Unidad de Posgrado de la Universidad Nacional Mayor de San Marcos (UNMSM). Profesor ordinario de la Facultad de Derecho y Ciencia Política de la Universidad Nacional Mayor de San Marcos (de 1990 a la fecha). Profesor contratado de la Facultad de Derecho Corporativo de la Universidad ESAN. 